\title{
Arterial Variations of the Subclavian-Axillary Arterial Tree: Its Association with the Supply of the Rotator Cuff Muscles
}

\author{
Variaciones Arteriales del Árbol Arterial Subclavio-Axilar. Su Asociación con la Irrigación del \\ Manguito de los Rotadores
}

N. Naidoo*; L. Lazarus*; B. Z. De Gama*; N. O. Ajayi* \& K. S. Satyapal ${ }^{*}$

NAIDOO, N.; LAZARUS, L.; DE GAMA, B. Z.; AJAYI, N. O. \& SATYAPAL, K. S. Arterial variations of the subclavian-axillary arterial tree: Its association with the supply of the rotator cuff muscles. Int. J. Morphol., 32(4):1436-1443, 2014.

SUMMARY: The subclavian-axillary arterial tree is responsible for the arterial supply to the rotator cuff muscles as well as other shoulder muscles. This study comprised the bilateral dissection of the shoulder and upper arm region in thirty-one adult and nineteen fetal cadaveric specimens. The variable origins and branching patterns of the axillary, subscapular, circumflex scapular, thoracodorsal, posterior circumflex humeral and suprascapular arteries identified in this study corroborated the findings of previous studies. In addition, unique variations that are unreported in the literature were also observed. The precise anatomy of the arterial distribution to the rotator cuff muscles is important to the surgeon and radiologist. It will aid proper interpretation of radiographic images and avoid injury to this area during surgical procedures.

KEY WORDS: Subclavian-axillary arterial tree; Variations; Supply; Rotator cuff muscles.

\section{INTRODUCTION}

Standard anatomical textbooks divide the axillary artery into three parts using its relation to the pectoralis minor muscle (Salopek et al., 2007). The first part of the axillary artery is situated superior to the pectoralis minor muscle and usually gives rise to one branch only - viz. the superior thoracic artery (Standring et al., 2008). The second part of the axillary artery lies deep to the pectoralis major and minor muscles. The two branches that commonly arise from the second part of the axillary artery are the thoraco-acromial and the lateral thoracic arteries (Rockwood et al., 2009). The third part of the axillary artery is typically inferior to the pectoralis minor muscle and generally gives rise to three branches - viz. subscapular and anterior and posterior circumflex humeral arteries (Standring et al.).

The suprascapular, circumflex scapular, posterior circumflex humeral and the subscapular arteries have been identified to contribute to the vascularity of the rotator cuff muscles (Sinnatamby, 2006). Variation in the origin, course and distribution of the principal arteries to the rotator cuff musculature is a common occurrence (Desai et al., 2011). Bergman et al. (2006) reported that the axillary artery may be represented as two vessels which arise from the first part of the subclavian artery. The subscapular artery has been identified by Saralaya et al. (2008) to arise as a large collateral branch from the first part of the axillary artery along the medial border of the pectoralis minor muscle. According to Huelke (2005), the rare origin of the circumflex scapular artery independently from the third part of the axillary artery was characteristic of an absent subscapular artery. Subsequently, Salopek et al. found the circumflex scapular, thoracodorsal and posterior circumflex humeral arteries to arise from a common trunk of the subscapular artery. Generally the rare origin of the suprascapular artery is characteristic of an absent thyrocervical trunk (Yücel et al., 1999).

The aim of this study was to describe the possible variations of the subclavian-axillary arterial tree.

\section{MATERIAL AND METHOD}

This study was performed at the Department of Clinical Anatomy, University of KwaZulu-Natal, Durban, South Africa. It was conducted in accordance with Chapter 8 of the National Health Act No. 61 of 2003. Ethical clearance

\footnotetext{
* Department of Clinical Anatomy, School of Laboratory Medicine and Medical Sciences, College of Health Sciences, University of KwaZulu-Natal, Durban, South Africa.
} 
was obtained from the relevant institutional authority (Ethical Clearance Approval Number: LMMSEC 003/12). The anterior and posterior aspects of the scapular and axillary regions of thirty-one adult and nineteen fetal cadaveric specimens were bilaterally dissected. The fetal specimens were bilaterally micro dissected with the use of a micro dissector and a microscope (Stemi DV4 by Carl Zeiss AG, Germany). Variation from the classical branching patterns of the subclavian and axillary arteries with their relative branches were identified and noted. The statistical analysis comprised the comparisons of right and left, and that of adult and fetal subsets. It was performed using SPSS version 19.0 (SPSS Inc., Chicago, Illinois, USA). A p value of $<0.05$ was considered to be statistically significant.

\section{RESULTS}

\section{Axillary artery}

i) Normal. The axillary artery continued as a single trunk from the outer border of the first rib to the inferior border of the teres major muscle in $90 \%$ of specimens ( $\mathrm{n}=90 / 100$ [right 44/50; left 46/50]). The comparison of fetal and adult subsets yielded a $\mathrm{p}$ value of 0.026 (Table I).

ii) Variation. In 5\% of specimens ( $n=5 / 100$ [right $2 / 50$; left $3 / 50]$ ), the second part of the axillary artery bifurcated deep to the pectoralis minor and major muscles (Table II; Figure 1). The bifurcation of the third part of the axillary artery inferior to the pectoralis minor muscle was seen in $5 \%$ of specimens $(n=5 / 100$ [right $4 / 50$; left $1 / 50]$ ).

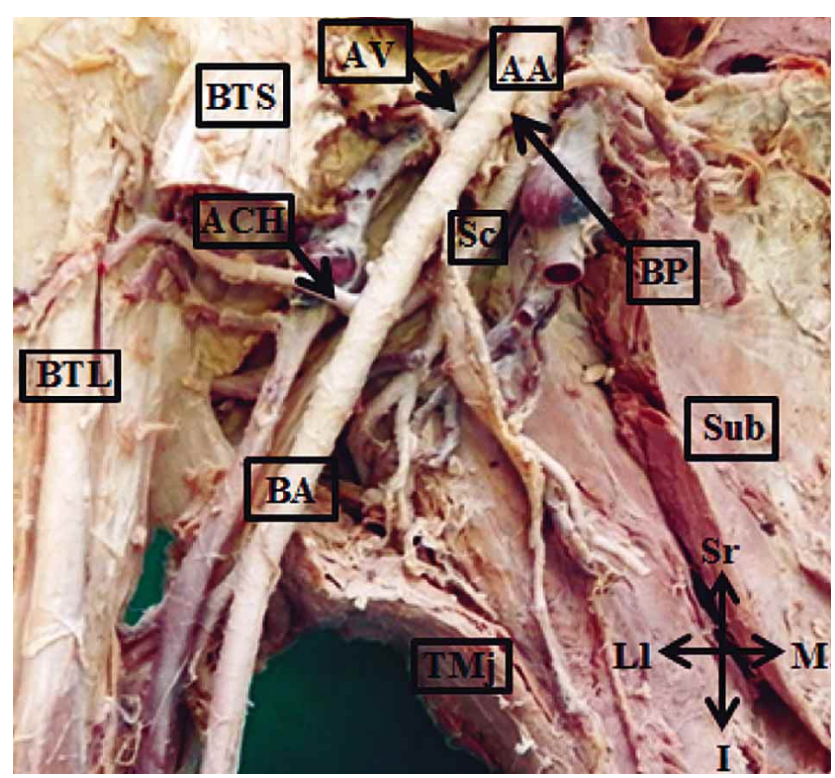

Fig. 1. Bifurcation of the second part of the axillary artery. AA= Axillary artery; $\mathrm{ACH}=$ Anterior circumflex humeral artery; $\mathrm{AV}=$ Axillary vein; $\mathrm{BA}=\mathrm{Brachial}$ artery; $\mathrm{BP}=\mathrm{Bifurcation}$ point; $\mathrm{BTL}=$ Tendon of long head of biceps brachii muscle; BTS= Tendon of short head of biceps brachii muscle; I= Inferior; Ll= Lateral; M= Medial; $\mathrm{Sc}=$ Subscapular artery; $\mathrm{Sr}=$ Superior, $\mathrm{Sub}=$ Subscapularis muscle; $\mathrm{TMj}=$ Teres major muscle.

\section{Subscapular artery}

i) Normal. The subscapular artery displayed the classical branching pattern in $53 \%$ of specimens $(n=53 / 100$ [right 28/50; left 25/50]), as it arose independently from the third part of the axillary artery. The comparisons of fetal and adult subsets yielded a p value of 0.014 (Table I).

Table I. P Values reflecting the level of significance of the comparisons of right and left shoulders and that of adult and fetal subsets.

\begin{tabular}{lccc}
\hline \multirow{2}{*}{ Artery } & & \multicolumn{2}{c}{ P Values } \\
\cline { 3 - 4 } Axillary & Normal & $\begin{array}{c}\text { Comparison of Right \& } \\
\text { Left Sides }\end{array}$ & $\begin{array}{c}\text { Comparison of Right \& } \\
\text { Left Sides }\end{array}$ \\
& Variation & 0.916 & 0.026 \\
Subscapular & Normal & 0.068 & 0.197 \\
& Variation & 0.784 & 0.014 \\
Circumflex scapular & Normal & 0.164 & 0.095 \\
& Variation & 0.915 & 0.007 \\
Thoracodorsal & Normal & 0.046 & 0.214 \\
Posterior circumflex & Variation & $*$ No P values due to overlap in variation with other arteries \\
humeral & Normal & 1.000 & 0.003 \\
Suprascapular & Variation & 0.332 & 0.273 \\
& Normal & 1.000 & 0.560 \\
\hline
\end{tabular}


ii) Variation. In two percent of specimens ( $n=2 / 100$ [right $2 / 50$ only]), the subscapular artery originated independently from the first part of the axillary artery. However, it arose independently from the second part of the axillary artery in $27 \%$ of specimens ( $n=27 / 100$ [right 12/50; left 15/50]). The subscapular artery was found to arise with the posterior circumflex humeral artery from a common trunk of the third part of the axillary artery in $15 \%$ of specimens $(n=15 / 100$ [right 7/50; left 8/50]). In three percent of specimens ( $n=3 /$ 100 [right 1/50; left 2/50]), the subscapular artery arose with both the posterior and anterior circumflex humeral arteries from a common trunk of the third part of the axillary artery (Table II; Figure 2).

\section{Circumflex scapular artery}

i) Normal. In $88 \%$ of specimens ( $n=88 / 100$ [right $43 / 50$; left $45 / 50]$ ), the circumflex scapular artery illustrated the classical branching pattern as it arose independently from the subscapular artery. The comparison of fetal and adult subsets yielded a p value of 0.007 (Table I).

ii) Variation. In 3\% of specimens ( $n=3 / 100$ [right $1 / 50$; left $2 / 50]$ ), the circumflex scapular artery originated from the third part of the axillary artery, while in $6 \%$ of specimens $(n=6 / 100$ [right 3/50; left 3/50]), the circumflex scapular artery arose from a common trunk of the subscapular artery with the posterior circumflex humeral and thoracodorsal arteries. The circumflex scapular artery was also recorded to arise from a common trunk of the subscapular artery with the posterior circumflex humeral artery in $3 \%$ of specimens $(n=3 / 100$ [right 3/50; left 0/50]) (Table II; Figure 3). A p value of 0.046 was recorded for the comparison of right and left shoulders (Table I).

\section{Thoracodorsal artery}

i) Normal. The thoracodorsal artery arose independently from the subscapular artery in $94 \%$ of specimens $n=94 / 100$ [right 47/50; left 47/50]). The comparison of fetal and adult subsets yielded a p value of 0.017 (Table I).

ii) Variation. As noted earlier, the thoracodorsal artery originated with the circumflex scapular and posterior circumflex humeral arteries from a common trunk of the subscapular artery in six percent of specimens $(n=6 / 100$ [right 3/50; left 3/50]).

\section{Posterior circumflex humeral artery.}

i) Normal. The posterior circumflex humeral artery arose typically from the third part of the axillary artery in thirtynine percent of specimens $(n=39 / 100$ [right 19/50; left 20/ 50]). The comparison of fetal and adult subsets yielded a $p$ value of 0.003 (Table I).

ii) Variation. In $2 \%$ of specimens ( $\mathrm{n}=2 / 100$ [right $1 / 50$; left 1/50]), the posterior circumflex humeral artery arose independently from the subscapular artery. The posterior circumflex humeral artery was found to arise with the anterior circumflex artery from a common trunk of the third part of the axillary artery in $31 \%$ of specimens $(n=31 / 100$ [right 14/50; left 17/50]). This vessel also arose with the anterior circumflex humeral and the profunda brachii arteries from a common trunk of the third part of the axillary artery in one specimen ( $\mathrm{n}=1 / 100$ [right 1/50; left 0/50]) (Table II; Figure 4). In the remaining $27 \%$ of specimens $(n=27 / 100$ [right 14/50; left 13/40]), the posterior circumflex humeral artery arose from a common trunk with other arteries - viz. the

Table II. Incidence ( $\mathrm{n}$ of specimens) of the unique variations of the subclavian-axillary arterial tree relating to the supply of the rotator cuff muscles $(n=100)$.

\begin{tabular}{|c|c|c|c|c|c|c|c|}
\hline \multirow{4}{*}{$\begin{array}{l}\text { Origin } \\
\text { Branches }\end{array}$} & \multicolumn{7}{|c|}{ Variation } \\
\hline & \multirow{3}{*}{$\begin{array}{c}\text { Bifurcation } \\
\text { site } \\
\text { 2nd part } \\
\text { axillary a. } \\
\text { - }\end{array}$} & \multicolumn{4}{|c|}{ Common Trunk } & \multicolumn{2}{|c|}{ Independently } \\
\hline & & \multicolumn{2}{|c|}{$\begin{array}{c}3 \mathrm{r}^{\mathrm{d}} \text { part } \\
\text { axillary a. }\end{array}$} & \multirow{2}{*}{$\begin{array}{c}\begin{array}{c}\text { Subscapular } \\
\text { artery }\end{array} \\
\mathrm{CS}+\mathrm{PCH}\end{array}$} & \multirow{2}{*}{$\begin{array}{c}3^{\text {rd }} \text { part } \\
\text { subclavia a. } \\
\text { DSA + Su }\end{array}$} & \multirow{2}{*}{$\begin{array}{c}\begin{array}{c}\text { 2nd part } \\
\text { axillary a. }\end{array} \\
-\end{array}$} & \multirow{2}{*}{$\begin{array}{c}\begin{array}{c}1^{\text {st }} \text { part } \\
\text { subcla via a. }\end{array} \\
\mathrm{VA}+\mathrm{Su}\end{array}$} \\
\hline & & $\begin{array}{c}\mathrm{Sc}+\mathrm{PCH} \\
+\mathrm{ACH}\end{array}$ & $\begin{array}{c}\mathbf{P C H}+ \\
\mathrm{ACH}+\mathrm{PB}\end{array}$ & & & & \\
\hline $\begin{array}{l}\text { Right } \\
(n=50)\end{array}$ & 2 & 1 & 1 & 3 & 1 & 10 & 0 \\
\hline $\begin{array}{l}\text { Left } \\
(n=50)\end{array}$ & 3 & 2 & 0 & 0 & 0 & 7 & 1 \\
\hline $\begin{array}{l}\text { Total } \\
(n=100)\end{array}$ & 5 & 3 & 1 & 3 & 1 & 17 & 1 \\
\hline
\end{tabular}

$\mathrm{ACH}=$ Anterior circumflex humeral artery; $\mathrm{CS}=$ Circumflex scapular artery; DSA= Dorsal scapular artery; $\mathrm{PCH}=$ Posterior circumflex humeral artery; $\mathrm{PB}=$ Profunda brachii artery; $\mathrm{Sc}=$ Subscapular artery; $\mathrm{Su}=$ Suprascapular artery; VA= Vertebral artery. 
subscapular, circumflex scapular, anterior circumflex humeral and thoracodorsal arteries.

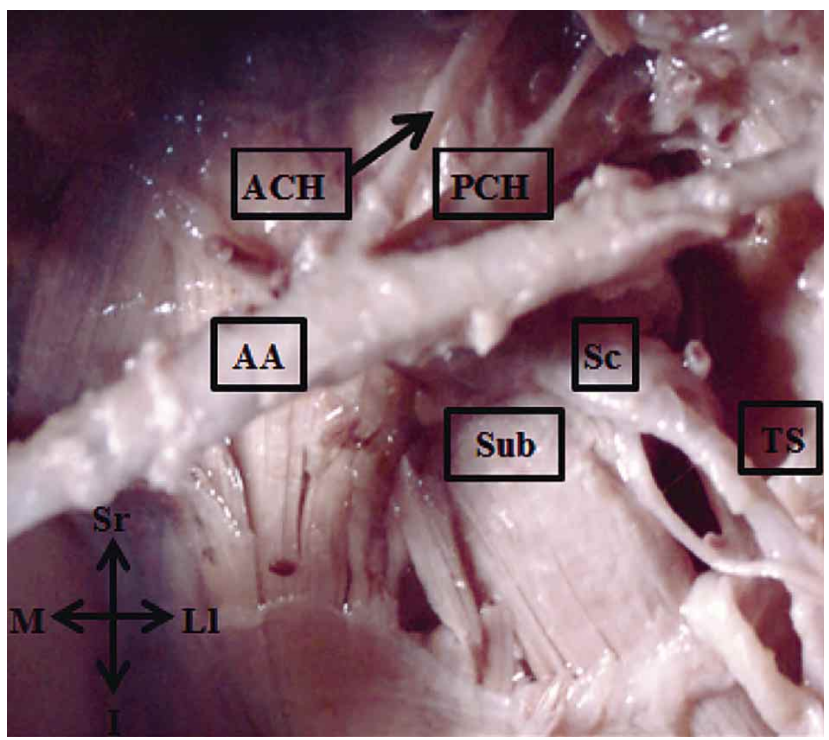

Fig. 2. Subscapular, posterior circumflex humeral and anterior circumflex humeral arteries arising from a common trunk of the third part of the axillary artery. AA= Axillary artery; $\mathrm{ACH}=\mathrm{An}$ terior circumflex humeral artery; $\mathrm{I}=$ Inferior; $\mathrm{Ll}=\mathrm{Lateral}$; $\mathrm{M}=$ Medial; $\mathrm{PCH}=$ Posterior circumflex humeral artery; $\mathrm{Sc}=$ Subscapular artery; $\mathrm{Sr}=$ Superior, $\mathrm{Sub}=$ Subscapularis muscle; $\mathrm{TS}=$ Triangular space.

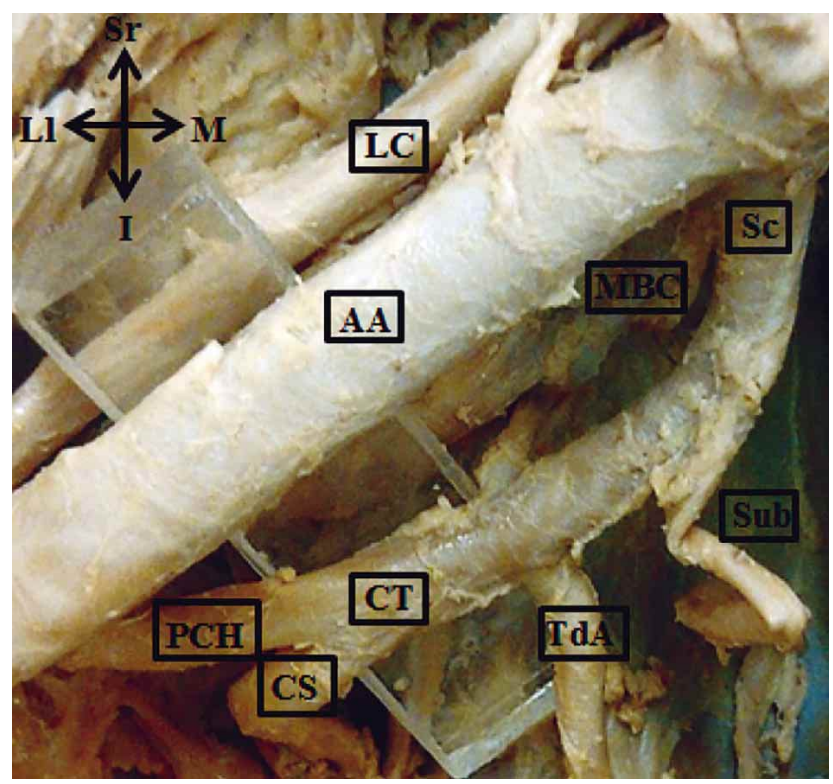

Fig. 3. Circumflex scapular and posterior circumflex humeral arteries arising from the common trunk of the subscapular artery. $\mathrm{AA}=$ Axillary artery $; \mathrm{CT}=$ Common trunk $\mathrm{CS}=$ Circumflex scapular artery; ; I= Inferior; Ll= Lateral; M= Medial; $\mathrm{MBC}=$ Medial brachial cutaneous nerve; $\mathrm{PCH}=$ Posterior circumflex humeral artery; $\mathrm{Sc}=$ Subscapular artery; $\mathrm{Sr}=$ Superior, $\mathrm{Sub}=$ Subscapularis muscle; TdA= Thoracodorsal artery.

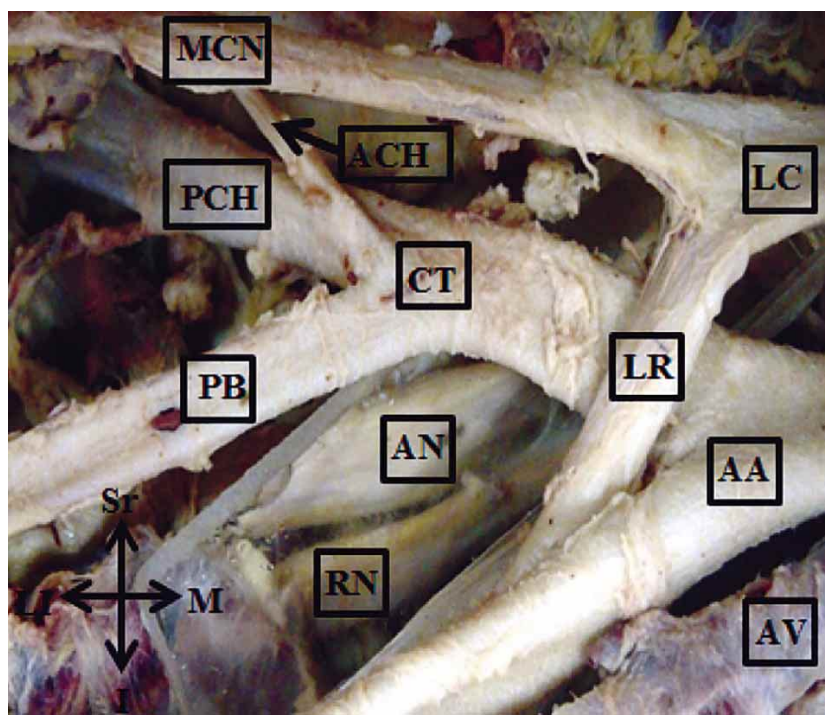

Fig. 4. Posterior circumflex humeral, anterior circumflex humeral and profunda brachii arteries arising from a common trunk of the third part of the axillary artery. $\mathrm{AA}=$ Axillary artery; $\mathrm{ACH}=$ Anterior circumflex humeral artery; $\mathrm{AN}=$ Axillary nerve; $\mathrm{AV}=$ Axillary vein; $\mathrm{CT}=$ Common trunk; $\mathrm{I}=$ Inferior; $\mathrm{LC}=$ Lateral cord of brachial plexus; $\mathrm{Ll}=$ Lateral; $\mathrm{LR}=$ Lateral root of median nerve; $\mathrm{M}=$ Medial; $\mathrm{MCN}=$ Musculocutaneous nerve; $\mathrm{PB}=$ Profunda brachii artery; $\mathrm{PCH}=$ Posterior circumflex humeral artery; $\mathrm{RN}=$ Radial nerve; $\mathrm{Sr}=$ Superior.

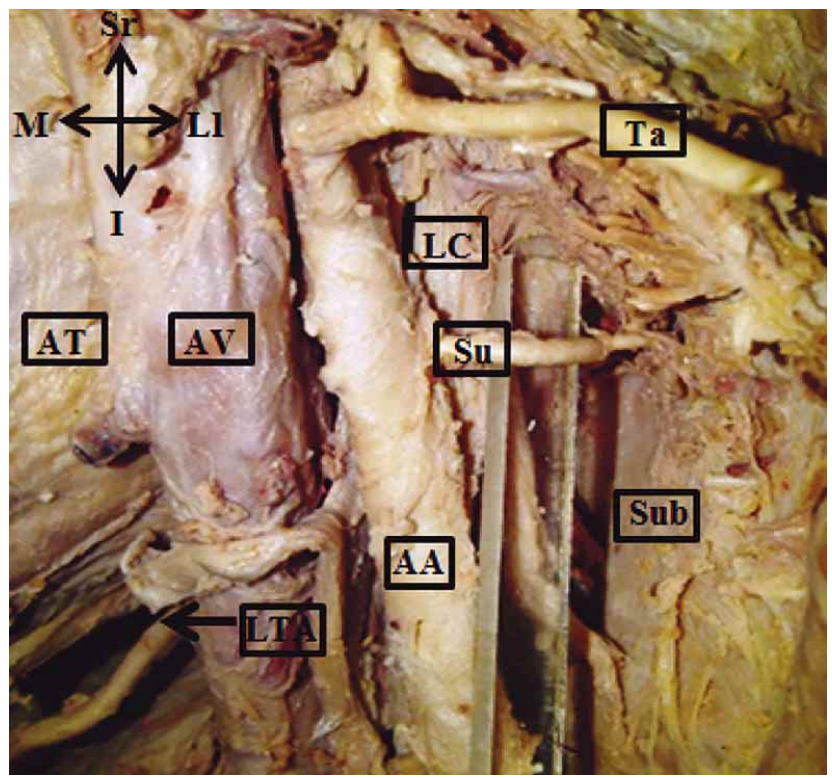

Fig. 5. Suprascapular artery arising from the second part of axillary artery. $\mathrm{AA}=$ Axillary artery; $\mathrm{AV}=$ Axillary vein; $\mathrm{AT}=$ Anterior thoracic wall; $\mathrm{I}=$ Inferior; $\mathrm{LC}=$ Lateral cord of brachial plexus; $\mathrm{Ll}=$ Lateral; $\mathrm{LTA}=$ Lateral thoracic artery; $\mathrm{M}=$ Medial; $\mathrm{Sr}=$ Superior; $\mathrm{Su}=$ Suprascapular artery; $\mathrm{Sub}=$ Subscapularis muscle; $\mathrm{Ta}=$ Thoracoacromial artery. 


\section{Suprascapular artery}

i) Normal. The classical branching pattern of the suprascapular artery (the origin of the suprascapular artery from the thyrocervical trunk) was displayed in forty-three percent of specimens $(n=43 / 100$ [right 21/50; left 22/50]) as it arose independently from the thyrocervical trunk.

ii) Variation. The suprascapular artery arose directly from the first and second parts of the axillary artery in $16 \%(n=16 /$ 100 [right 7/50; left 9/50]) and 17\% $(n=17 / 100$ [right 10/50;

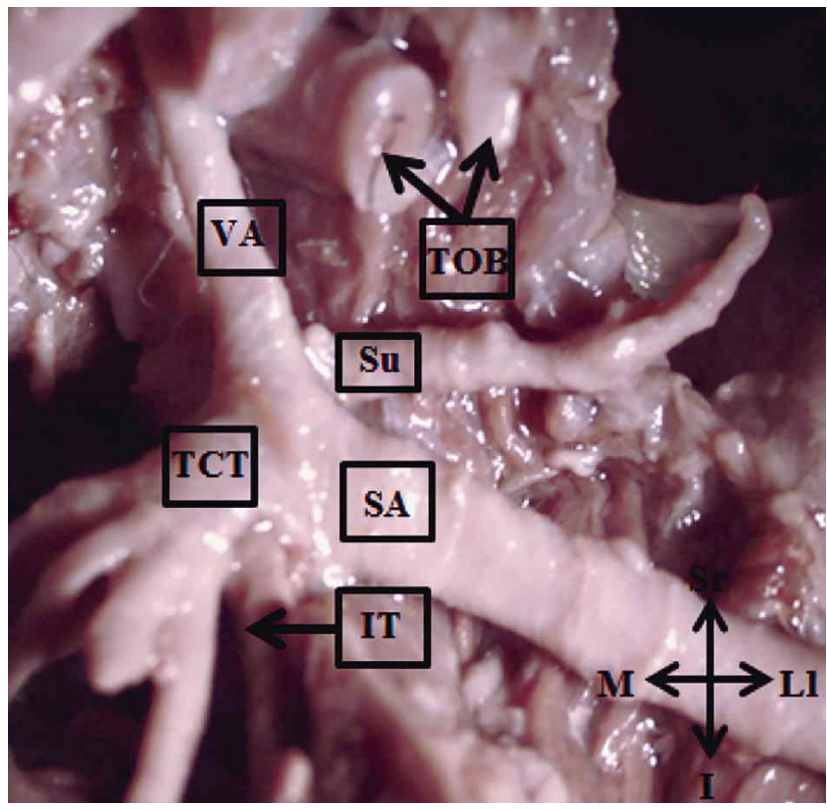

Fig. 6. Suprascapular artery arising from the vertebral artery of the first part of the subclavian artery. I= Inferior; IT= Internal thoracic artery; Ll= Lateral; M= Medial; SA= Subclavian artery; $\mathrm{Sr}=$ Superior; $\mathrm{Su}=$ Suprascapular artery; $\mathrm{TCT}=$ Thyrocervical trunk; $\mathrm{TOB}=$ Trunks of brachial plexus.

\section{DISCUSSION}

According to Maral et al. (1993), "a basic law of vascular anatomy is that the only thing which remains constant is its variability". The origin, course and branching pattern of the subclavian-axillary arterial system is subject to a great deal of variation (Gaur et al., 2012). Arey (1962) stated that arterial variations arise from the arrest of an embryonic stage during the development of the primitive vascular network, which may be characterized by the persistence, regression or recurrence of arteries.

Recently, the axillary artery has been identified as the artery of choice of the upper limb for vascular bypass and ligation in vascular surgery (Srimathi, 2011). In this left 7/50]) of specimens respectively (Table II; Figure 5). It arose independently from the subscapular artery of the third part of the axillary artery in $3 \%$ of specimens $(n=3 / 100$ [right $2 / 50$; left 1/50]). In one specimen ( $\mathrm{n}=1 / 100$ [left $1 / 50$ only]), the suprascapular artery arose from the vertebral artery (Table II; Figure 6). The suprascapular artery arose directly from the third part of the subclavian artery in nineteen percent of specimens $(n=19 / 100$ [right $9 / 50$; left $10 / 50])$. It was also seen to arise with the dorsal scapular artery from a common trunk of the third part of the subclavian artery in one specimen $(n=1 / 100$ [right $1 / 50$ only]) (Table II; Figure 7$)$.

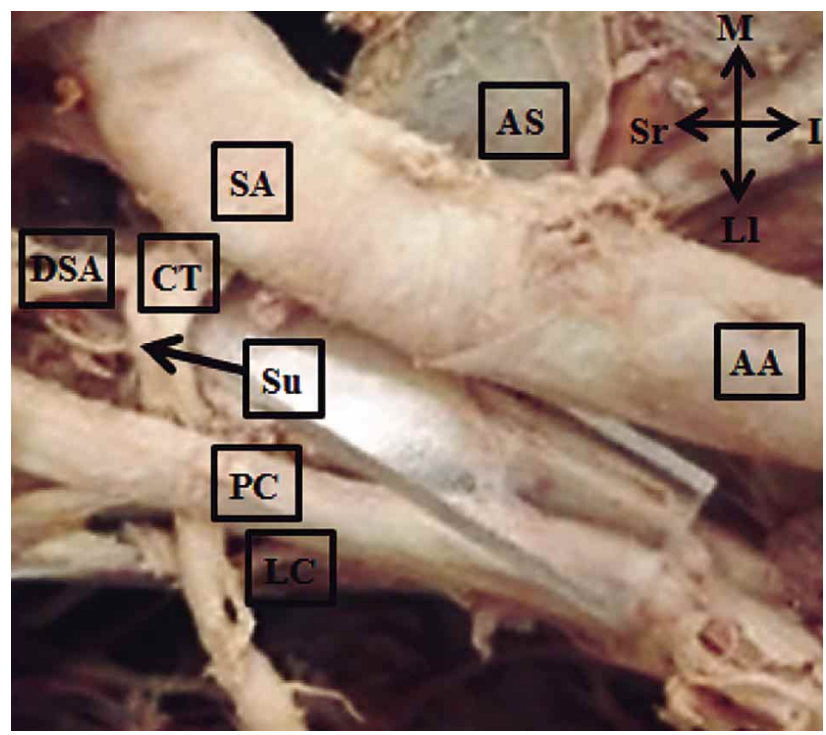

Fig. 7. Suprascapular and dorsal scapular arteries arising from a common trunk from the third part of the subclavian artery. AA= Axillary artery; $\mathrm{AS}=$ Serratus anterior muscle; $\mathrm{CT}=\mathrm{Common}$ trunk; $\mathrm{DSA}=$ Dorsal scapular artery; $\mathrm{I}=$ Inferior; $\mathrm{LC}=$ Lateral cord of brachial plexus; $\mathrm{Ll}=$ Lateral; $\mathrm{M}=$ Medial; $\mathrm{PC}=$ Posterior cord of brachial plexus; $\mathrm{SA}=$ Subclavian artery; $\mathrm{Sr}=$ Superior; $\mathrm{Su}=$ Suprascapular artery.

study, the second part of the axillary artery bifurcated in 5\% of specimens; this finding appears to be unique as it has not been described in the literature reviewed. The bifurcation of the third part of the axillary artery was seen in $5 \%$ of specimens as reported in previous studies (Cavdar et al., 2000; George et al., 2007; Desai et al.; Kachlik et al., 2011). A statistically significant $\mathrm{p}$ value of 0.026 was recorded between adult and fetal subsets for the classical branching pattern of the axillary artery only.

Valnicek et al. (2004) stated that the subscapular artery was an "ideal donor" as its branches could be harvested and used as an arterial graft to replace diseased or damaged 
parts of arteries in the upper limb. Despite the ability to meet the criteria to be used as a source of microvascular arterial grafts, the unpredictable anatomy of the subscapular arterial tree is apparent. The origin of the subscapular artery as a large collateral branch from the first part of the axillary artery occurred in $2 \%$ of specimens in this study, which corroborated the report of Saralaya et al. The rare origin of the subscapular artery from the second part of the axillary artery was recorded in $27 \%$ of specimens in the current study and compared favorably with earlier studies (Huelke, 2005; Bergman et al.; Daimi et al., 2010; Karambelkar et al., 2011; Gaur et al.). Lippert \& Pabst (1985), Saeed et al. (2002) and Karambelkar et al. (2011) reported the origin of the subscapular artery with the posterior circumflex humeral artery from a common trunk of the third part of the axillary artery. This observation was confirmed in $15 \%$ of specimens of the present study. In 3\% of specimens, the subscapular artery arose with the anterior and posterior circumflex humeral arteries from a common trunk of the third part of the axillary artery. This variation is also not described in the literature reviewed. A statistically significant $p$ value of 0.014 was recorded between adult and fetal subsets for the classical branching pattern of the subscapular artery.

The circumflex scapular artery arose independently from the third part of axillary artery in 3\% of specimens which was observed in previous studies (Valnicek et al.; Huelke; Gaur et al.). The origin of the circumflex scapular artery with the posterior circumflex humeral and thoracodorsal arteries from a common trunk of the subscapular artery as reported by Salopek et al., was confirmed in this study. The origin of the circumflex scapular artery with the posterior circumflex humeral artery from a common trunk of the subscapular artery was recorded in $3 \%$ of specimens. This finding has also not been described in the literature reviewed. Statistically significant $\mathrm{p}$ values of 0.007 and 0.046 were recorded between adult and fetal subsets and laterality for the classical branching pattern and variation of the circumflex scapular artery respectively.

Rockwood et al. and Standring et al. recorded the origin of the thoracodorsal artery from the subscapular artery, which was displayed in $94 \%$ of specimens in this study. A statistically significant $\mathrm{p}$ value of 0.017 was recorded between adult and fetal subsets for the classical branching pattern of the thoracodorsal artery.

In this study, the posterior circumflex humeral artery arose independently from the subscapular artery in $2 \%$ of specimens which corroborated previous reports (Huelke; Bhat et al., 2008; Goldman, 2008). The posterior circumflex humeral artery was found to arise with the anterior circumflex humeral artery from a common trunk of the third part of the axillary artery in $31 \%$ of specimens, which concurred with the studies conducted by Lippert \& Pabst and Huelke. In $1 \%$ of specimens, the anterior and posterior circumflex humeral and profunda brachii arteries arose through a common trunk from the third part of the axillary artery. This variation has also not been described in the literature reviewed. A statistically significant $\mathrm{p}$ value of 0.003 was recorded between adult and fetal subsets for the classical branching pattern of the posterior circumflex humeral artery.

Mishra \& Ajmani (2003) and Adibatti \& Prasanna (2010) observed the origin of the suprascapular artery from the first part of the axillary artery, which was confirmed in $16 \%$ of specimens of this study. The suprascapular artery arose from the third part of the subclavian artery in 19\% of specimens concurring with the study conducted by Bergman et al. In $17 \%$ of specimens the suprascapular artery arose from the second part of the axillary artery while in $1 \%$ of specimens it arose independently from the vertebral artery. In addition, the suprascapular artery was noted to arise with the dorsal scapular artery from a common trunk of the third part of the subclavian artery in $1 \%$ of specimens. These observations are unique, as they have not been described in previous literature. No significant p values were obtained.

The significant $\mathrm{p}$ values that were recorded between adult and fetal subsets for the respective arteries may be regulated by certain factors such as nutrient and oxygenation requirements, genotype, haemodynamics, environmental influences as well as the natural process of evolution (Weinstein, 1999; Rodriguez-Niedenfuhr et al., 2001).

\section{CONCLUSION}

In this study the most common variations included the origin of the subscapular artery from the second part of the axillary artery (27\%), origin of the suprascapular artery from the third part of the subclavian artery or a branch of it (20\%), and the origin of the anterior and posterior circumflex humeral arteries from a common trunk of the third part of the axillary artery (30\%). Variation of the axillary, subscapular, circumflex scapular, thoracodorsal, posterior circumflex humeral and suprascapular arteries were extensive as many unique variations were identified. The unique variations recorded in this study were the bifurcation of the second part of the axillary artery (5\%), origin of the subscapular, anterior and posterior circumflex humeral arteries from a common trunk of the third part of the axillary artery $(3 \%)$, origin of the circumflex scapular and posterior circumflex humeral arteries from a common trunk of the subscapular artery (3\%), origin of the anterior and posterior 
circumflex humeral and profunda brachii arteries from a common trunk of the third part of the axillary artery $(1 \%)$, origin of the suprascapular artery from the second part of the axillary artery $(17 \%)$, origin of the suprascapular artery from the vertebral artery $(1 \%)$ and lastly the origin of the suprascapular and dorsal scapular arteries from a common trunk of the third part of the subclavian artery $(1 \%)$.
The results of this study may be clinically advantageous to both the clinician and the patient, as it may contribute to advances in reconstructive surgery as well as enhance the quality of life. Furthermore, the knowledge of the gross vascular anatomy may also assist in the appropriate therapeutic management of injuries in and around the subclavian-axillary arterial system, thus preventing arterial insufficiency of the upper limb.

NAIDOO, N.; LAZARUS, L.; DE GAMA, B. Z.; AJAYI, N. O. \& SATYAPAL, K. S. Variaciones arteriales del árbol arterial subclavioaxilar: Su asociación con la irrigación del manguito de los rotadores. Int. J. Morphol., 32(4):1436-1443, 2014.

RESUMEN: El árbol arterial subclavio-axilar, es responsable del suministro arterial de los músculos correspondientes al manguito de los músculos rotadores, así como de otros músculos del hombro. Este estudio comprende la disección bilateral del hombro y la región superior del brazo en 31 cadáveres adultos y 19 fetos. Las variables y patrones del origen, ramificación de las arterias axilar, subescapular, circunfleja escapular, toracodorsal, circunfleja humeral posterior y supraescapular, identificados en este estudio, corroboran los hallazgos de estudios anteriores. Además, se observaron variaciones únicas no comunicadas previamente en la literatura. La anatomía precisa de la distribución arterial de los músculos del manguito de los músculos rotadores es importante para el cirujano y el radiólogo. Esta información constituirá una ayuda para la adecuada interpretación de imágenes radiológicas y para evitar lesiones en esta área durante los procedimientos quirúrgicos.

PALABRAS CLAVE: Árbol arterial subclavio-axilar; Variaciones; Irrigación; Músculos del manguito de los rotadores.

\section{REFERENCES}

Adibatti, M. \& Prasanna, L. C. Variation in origin of suprascapular artery. Int. J. Anat. Var., 3:178-9, 2010.

Arey L. B. Developmental Anatomy: A Textbook and Laboratory Manual of Embryology. $7^{\text {th }}$ ed. Philadelphia, W. B. Saunders Company, 1962.

Bergman, R. A.; Afifi, A. K. \& Miyauchi, R. Illustrated Encyclopedia of Human Variation. 2006. Available in: http:/ /www.anatomyatlases.org

Bhat, K. M.; Gowda, S.; Potu, B. K. \& Rao, M. S. A unique branching pattern of the axillary artery in a South Indian male cadaver. Bratisl. Lek. Listy, 109(12):587-9, 2008.

Cavdar, S.; Zeybek, A. \& Bayramiçli, M. Rare variation of the axillary artery. Clin. Anat., 13(1):66-8, 2000.

Daimi, S. R.; Siddiqui, A. U. \& Wabale, R. N. Variations in the branching pattern of axillary artery with high origin of radial artery. Int. J. Anat. Var., 3:76-7, 2010.

Desai, S. D.; Sreepadma, S. \& Rathnakar, P. Anomalous division of axillary artery - A case report. Anat. Karnataka, 5(2):5760, 2011.

Gaur, S.; Katariya, S. K.; Vaishnani, H.; Wani, I. N.; Bondre, K. V. \& Shah, G. V. A cadaveric study of branching pattern of the axillary artery. Int. J. Biol. Med. Res., 3(1):1388-91, 2012.
George, B. M.; Nayak, S. \& Kumar, P. Clinically significant neurovascular variations in the axilla and the arm - A case report. Neuroanat., 6(1):36-8, 2007.

Goldman, E. M. Axillary artery and branch variations in an 83 year-old male Caucasian. FASEB J., 22:770-6, 2008.

Huelke, D. F. Variation in the origins of the branches of the axillary artery. Anat. Rec., 135(1):33-41, 2005.

Kachlík, D.; Konarík, M.; Urban, M. \& Báca, V. Accessory brachial artery: a case report, embryological background and clinical relevance. Asian Biomed., 5:151-5, 2011.

Karambelkar, R. R.; Shewale, A. D. \& Umarji, B. N. Variations in branching pattern of axillary artery and its clinical significance. Anat. Karnataka, 5(2):47-51, 2011.

Lippert, H. \& Pabst, R. Arterial Variations in Man: Classification \& Frequency. Munich, J.F. Bergman Verlag, 1985.

Maral, T.; Celik, H.; Hayran, M. \& Kecik, A. An anatomical variation of the thoracodorsal artery with comments on flaps based on the axillary artery. Eur. J. Plast. Surg. 16(4-5):231-3, 1993.

Mishra, S. \& Ajmani, M. L. Anomalous origin of suprascapular artery. J. Anat. Soc. India, 52(2):180-2, 2003.

Rockwood, C. A. Jr.; Matsen III, F. A.; Wirth, M. A. \& Lippitt, S. B. The Shoulder. $4^{\text {th }}$ ed. Philadelphia, Saunders Elsevier, 2009. 
NAIDOO, N.; LAZARUS, L.; DE GAMA, B. Z.; AJAYI, N. O. \& SATYAPAL, K. S. Arterial variations of the subclavian-axillary arterial tree: Its association with the supply of the rotator cuff muscles. Int. J. Morphol., 32(4):1436-1443, 2014.

Rodríguez-Niedenführ, M.; Burton, G. J.; Deu, J. \& Sanudo, J. R. Development of the arterial pattern in the upper limb of staged human embryos: normal development and anatomic variations. J. Anat., 199(Pt. 4):407-17, 2001.

Saeed, M.; Rufai, A. A.; Elsayed, S. E. \& Sadiq, M. S. Variations in the subclavian-axillary arterial system. Saudi. Med. J., 22(2):206-12, 2002.

Salopek, D.; Dujmovic, A.; Hadjina, J. \& Topic, I. Bilateral arterial and nervous variations in the human upper limb: a case report. Ann. Anat., 189(3):290-4, 2007.

Saralaya, V.; Joy, T.; Madhyastha, S.; Vadgaonkar, R. \& Saralaya, S. Abnormal branching of the axillary artery: Subscapular common trunk. Int. J. Morphol. 26(4):963-6, 2008.

Sinnatamby, C. S. Last's Anatomy: Regional \& Applied. New York, Churchill Livingstone/Elsevier, 2006.

Srimathi, T. Abnormal branching pattern of the axillary artery - A case report. Int. J. Basic Med. Sci., 2(4):73-6, 2011.

Standring, S. Gray's Anatomy: The Anatomical Basis of Clinical Practice. $40^{\text {th }}$ ed. Madrid, Elsevier, 2008.

Valnicek, S. M.; Mosher, M.; Hopkins, J. K. \& Rockwell, W. B. The subscapular arterial tree as a source of microvascular arterial grafts. Plast. Reconstr. Surg., 113(7):2001-5, 2004.

Weinstein, B. M. What guides early embryonic blood vessel formation? Dev. Dyn., 215(1):2-11, 1999.

Yücel, A. H.; Kizilkanat, E. \& Ozdemir, C. O. The variations of the subclavian artery and its branches. Okajimas. Folia Anat. Jpn., 76(5):255-61, 1999.

\author{
Correspondence to: \\ Professor K. S. Satyapal \\ Department of Clinical Anatomy \\ School of Laboratory Medicine and Medical Sciences \\ College of Health Sciences \\ University of KwaZulu-Natal \\ Private Bag X54001 \\ Durban \\ 4000 \\ SOUTH AFRICA
}

Email: satyapalk@ukzn.ac.za

Received: 08-01-2014

Accepted: 11-07-2014 